Intervención

\title{
La revuelta entre otras revueltas: los feminismos antes y más allá del octubre chileno
}

\author{
Karen Glavic* \\ *UNIVERSIDAD DE CHILE
}

\section{Presentación}

Esta Intervención repara en tres libros estratégicos para el análisis de la movilización y reflexión feministas imprescindibles para dar cuenta del "octubre" chileno en tanto marco fundamental dentro del cual se vienen incubando y sucediendo una serie de revueltas anteriores. En este caso se trata de aproximaciones críticas y otras más afines al fenómeno de la revuelta feminista en Chile, de la mano de las filósofas Alejandra Castillo y Aïcha Messina y del libro de la psicoanalista Constanza Michelson. Aunque no de manera idéntica, en los diferentes registros encontramos intentos por aprehender críticamente su fenómeno y su potencia, su necesidad y su urgencia, y también sus límites y sus riesgos.

\section{Introducción}

Los feminismos han sido protagonistas durante los últimos años de masivas movilizaciones sociales, una prolífica producción teórica y también una serie de discusiones motivadas por sus incisivas interpelaciones al orden androcéntrico. Su expansión como movimiento y sus reflexiones no han estado exentas de dificultades y polémicas, tanto por las necesarias demandas de justicia que han dirigido hacia el orden de dominación patriarcal existente, como por sus herramientas políticas y algunas derivas identitarias y punitivas. En el inicio del párrafo menciono que se trata de feminismos, un plural que hace décadas está instalado como, tal vez, la forma más precisa de referirse a la gran diversidad de producciones teóricas

y activismos feministas. Algo de esas diferencias teóricas, pero también intuiciones y reflexiones que no provienen necesariamente del campo de la teoría feminista, es lo que revisaremos en los ensayos de la psicoanalista Constanza Michelson y las filósofas Alejandra 
Castillo y Aïcha Liviana Messina, todos publicados entre diciembre de 2019 y enero de 2020 en Santiago de Chile.

A estos ensayos y crónicas los describe el formato-fragmento. Una escritura con carácter de urgencia que tuvo como primera publicación, para buena parte de los escritos compilados, medios de comunicación digitales como periódicos o blogs. Estos buscaron una rápida circulación que necesitaba atender al momento, intentar darle sentido a escenas que asaltaban la vista, que conmovían, que movilizaban ciertos afectos, que querámoslo o no, llamaron a la escritura de estas autoras en tanto que mujeres y en tanto que feministas. Hago la distinción porque creo que es pertinente, aunque dejaré para más tarde algunas reflexiones en torno al problema de "ser feminista" en estos ensayos. No es sencillo seguir un único hilo para poder reflexionar sobre estas escrituras disímiles, aunque tal vez si se tratara de ubicarlos en alguna estantería temática de librería, todos cabrían en la denominación "feminismos". También, de cierta manera, en la categoría "revuelta de octubre", pero también son bastante más que eso.

Estos textos sobre la revuelta chilena de octubre de 2019 están cruzados por otras revueltas: por la gran marea feminista a la que asistimos desde hace algunos años en el país y en el continente. A veces parece que el estallido social las hubiera tomado por sorpresa en medio de otras reflexiones, y presentan trabajos llenos de preguntas (sobre todo para el caso de Messina y Michelson) sobre los feminismos, y varios “téngase presente feministas” en el caso de Castillo; estos últimos iban desde la necesidad de pensar en el cuerpo de la política, que repetiría su representación masculina y heteronormada -luego de que el acuerdo de noviembre desechara la posibilidad de una Asamblea Constituyente-, hasta el aviso previo de la revuelta feminista de mayo de 2018 que hizo sonar con anterioridad un fuerte "no más"1 a los abusos machistas.

\section{Tres detenciones necesarias}

Decía que los libros que aquí comentamos se mueven por caminos y exploraciones distintas. Es por esta razón que me parece relevante hacer una suerte de breve descripción sobre cada

\footnotetext{
${ }^{1}$ Alejandra Castillo, Asamblea de los cuerpos (Santiago: Sangría Editora, 2019), 37.
} 
uno de ellos antes de sugerir una lectura que los aúne y ponga en perspectiva. Comenzaré por Feminismo y revolución. Crónica de una inquietud. Santiago 2019. Fragmentos de una paz insólita de Aïcha Liviana Messina publicado por ediciones Metales Pesados. El título o los títulos ya se ofrecen bastante sugerentes, largos, sobrepuestos por la exigencia de decir algo sobre lo que octubre de 2019 hizo estallar ante los ojos de la autora. Tal como mencionamos previamente para el caso de los tres libros, este volumen está compuesto por artículos publicados en su mayoría en el periódico The Clinic en Chile y en la revista Esprit en Francia. La nota preliminar arroja inmediatamente una advertencia: este libro reflexiona a propósito de las movilizaciones feministas del 2018 en Chile y otros lugares del mundo, pero al momento de la entrega del manuscrito a la editorial, la revuelta del 18 de octubre impuso una suspensión de la escritura, del trabajo, una interrupción del sentido; trajo otro tiempo y otro orden que, sin señaléticas de tránsito, nos dejaba en una cierta anarquía, más un toque de queda que durante las noches arrojaba una quietud que Messina llama, como uno de los varios títulos de este libro: "una paz insólita".

Dije antes también que este libro y el de Michelson tratan más con preguntas que con certezas. Me parece importante este gesto, pues no creo que la teoría feminista haya abandonado las preguntas; pero es cierto que la materialidad de nuestras escrituras (y activismos) a veces impone no reaccionar con la soltura de quien puede situarse desde la escritura de la "crónica de una inquietud". Messina reconoce en el feminismo varias esperanzas. Lo ve como una forma de regenerar los cuerpos y los afectos, y cuando evoca la palabra revolución lo hace pensando en que el feminismo revoluciona la idea clásica de revolución, o más bien, instala la pregunta: ¿cómo podría el feminismo llevar esto a cabo? Sus referencias, las escenas que observa son disímiles. Por un lado, observa el poder que tuvo el \#MeToo tanto en Estados Unidos como la respuesta que provocó en Francia; y de otro lado, observa la revuelta del mayo feminista chileno y su inscripción particular en las universidades. Junto a la advertencia sobre el momento de entrega del manuscrito, Messina hace otras dos declaraciones que me parecen importantes de mencionar: no reflexionará desde una teoría feminista en específico, ni tampoco considerará para su escritura una posición situada:

La verdad es que espero nunca hacer esto de mí misma, nunca presentarme así dentro de un contexto académico, nunca partir 
un texto, una reflexión creyendo realmente que los seres, los cuerpos encajan con estas categorías evidentemente construidas. No solo en algunos lugares soy blanca, en otros tengo manchas. No solo mi sexo es algo que nunca ha sido simple. No solo las clases son las determinaciones más tristes que existen ${ }^{2}$.

Este pasaje es expuesto a propósito de cómo la autora ha escuchado en la universidad a colegas y estudiantes presentarse y hablar desde un lugar social y racialmente situado. Una perspectiva que, por cierto, se aleja de variados feminismos y feministas que, precisamente, consideran que la posición desde la cual se piensa, se escribe y se habla, nunca está desprovista de marcas raciales, étnicas, sexuales y genéricas. Y es cierto, el sexo de nadie ha sido nunca simple, pero ni las epistemologías feministas ni los conocimientos situados han apuntado a la simpleza. Hay aquí una toma de posición sustantiva de la autora, una entre otras. Para Messina el problema de la violencia pareciera ser central en los ensayos aquí recopilados. En este problema se anuda un punto fuerte y de atención para los feminismos, ya que con el ojo puesto en las denuncias por violencia sexual que se derivaron del movimiento \#MeToo, y en las funas y protocolos contra el acoso que emanaron de la revuelta del mayo feminista chileno, se instala un problema ineludible: cómo la homologación de toda situación de violencia sustancializa el Mal y reduce algunos individuos a encarnaciones de ese Mal radical. Desde aquí se pregunta por los linchamientos, por la suspensión del derecho que opera cuando no hay matices entre agresores y tipos de agresiones, cuando no hay derecho a defensa ni a presunción de inocencia. Por cierto, Messina no desconoce la violencia estructural contra las mujeres que estos hashtags visibilizan, pero instala su hipótesis de lectura en la idea de que el feminismo "que adquirió voz en 2018 -en una de sus aristasemergió (...) de la privatización del mundo y de los derechos, el debilitamiento de los Estados (o el pasaje del Estado de derecho al Estado de seguridad)" ${ }^{3}$ y que más que una nueva conciencia dada por un proceso histórico, esa degradación de la política en su dimensión pública hizo emerger reclamos privados ${ }^{4}$ que explotaron cuando el hogar dejó de oponerse a

\footnotetext{
${ }^{2}$ Aïcha Liviana Messina, Feminismo y revolución. Crónica de una inquietud. Santiago 2019. Fragmentos de una paz insólita (Santiago: Ediciones Metales Pesados, 2020), 22.

${ }^{3}$ Ibíd., 18.

${ }^{4}$ Ibidem.
} 
lo público. La hipótesis es arriesgada en dos dimensiones: de un lado, en no considerar la violencia contra las mujeres como un problema tan público que hace de la violación masiva, las prácticas eugenésicas y la desaparición forzada y la trata como botín de guerra más que un problema que "salió de la casa" y que ha sido prolíficamente estudiado por muchas teóricas feministas ${ }^{5}$. La segunda dimensión arriesgada es fijar la atención en los hashtags y no, efectivamente, en los procesos de organización, toma de conciencia y movilización de las mujeres en torno a la violencia, quienes a través de redes internacionalistas y organizaciones de apoyo mutuo y de seguridad han bregado durante décadas por denunciar la violencia que sufren las mujeres y las disidencias, tanto dentro como fuera de sus casas. No, es imposible afirmar que movimientos como el "Ni una menos" son solo un hashtag, o que no consideran la violencia clasista, racial o colonial. De ejemplos como estos la autora no toma nota, y lleva más allá la crítica: hay un problema con encarar el problema de la violencia solo desde el género. Por suerte hace ya tiempo contamos con categorías como "interseccionalidad" que problematizan bastante una hipótesis en esta dirección.

Tomando esta distancia de un argumento central del libro, quisiera de todas maneras detenerme en lo importante que resulta pensar en el problema de la degradación de la dimensión pública de la política. No es posible negar que esto ha ocurrido, ni que el auge del movimiento feminista ha coincidido con el declive de gobiernos progresistas o el alza de movimientos de extrema derecha, ni que en muchas ocasiones este movimiento puede encarnar la subjetividad de los Estados de seguridad: desconfianza, persecución, atomización. Pero hay que moverse con cuidado en el análisis de este terreno pantanoso, pues es posible observar que los movimientos feministas, que llevan décadas de organización, en otros momentos de la historia (de la chilena en los años ochenta del siglo pasado, sin ir más lejos) han servido de dinamizador y acicate para expandir los límites de las democracias

\footnotetext{
${ }^{5}$ Sobre este tema, pienso en referencias fundamentales como Rita Laura Segato, Verónica Gago y la relectura sobre la "guerra contra las mujeres", o la propuesta de pensar un cuerpo-territorio y las dimensiones coloniales y extractivistas de esta guerra y de estos cuerpos. De otro lado, clave es el ya célebre trabajo de Catherine Mackinnon, "Crímenes de guerra, crímenes de paz", en Los derechos humanos, las conferencias Oxford Amnesty de 1993, S. Shure y S. Hurley eds. (Madrid: Editorial Trotta, 1998), e incluso algunos de los escritos de Judith Butler podrían aportar a esta consideración sobre la violencia y lo problemático que resulta pensarla como un asunto privado. Hace un par de años también se desarrollan trabajos que explícitamente se definen como feminismo antipunitivo y anticarcelario, los argentinos Nicolás Cuello y Lucas Morgan tienen un compilatorio que ha circulado bastante por la red y que Michelson cita en su texto. Ver Nicolás Cuello y Lucas Morgan comps., Críticas sexuales a la razón punitiva. Insumos para seguir imaginando una vida junt*s (Neuquén: Ediciones Precarias, 2018).
} 
liberales o la cerrazón patriarcal de los movimientos revolucionarios. Es decir, en momentos de "degradación de lo público" inventan, desde otros imaginarios y formas de organizarse, salidas a la forma tradicional de hacer política.

¿Pero qué tiene de particular este momento, esta fase de la marea feminista que tomó una dimensión moral y punitiva? Messina acierta cuando plantea que no será esta la forma para cumplir la promesa feminista de una sociedad nueva, o cuando denuncia que la excesiva protocolización de las relaciones sexo-afectivas en la universidad o incluso en el tránsito por la calle, son señeros peligrosos para un feminismo que busca desjerarquizar la sociedad y la cultura. La hipótesis que propone para dar cuenta de este "giro punitivo" ya ha sido explicitada, y desde aquí quisiera empezar a anudar puntos en común con el texto Hasta que valga la pena vivir de Constanza Michelson, pero no sin antes mencionar que tanto el posfacio en que Messina declara su amor al "pequeño machista" Kafka o los fragmentos de una paz insólita de 2019 con los que este volumen cierra, cambian el tono del libro e introducen inflexiones interesantes, que están dadas por la coyuntura que llamó y las lecturas previas sobre la lengua materna, el feminismo y Kafka que la autora había ya explorado. Este último apartado no aspira a ser una columna de opinión, pues son derechamente fragmentos, pequeñas crónicas escritas desde la angustia habitando el cuerpo, desde la improductividad de una ciudad detenida. Allí habla del amor, de estallidos, de transgresiones, de cuerpos bailando en una fiesta que hace de este particular momento político una fiesta colectiva de todos o todes. De estos fragmentos destaco ese que Aïcha Liviana Messina llamó "Cabañas", en el que habla del amor y de cómo hoy los jóvenes prefieren tener amigos que relaciones de pareja. Su hipótesis es bella y esperanzadora:

En este ámbito, preferir la seguridad de la amistad al riesgo del amor no es una opción ideológica que apunte solo a la seguridad individual (no es la opción «neoliberal», si es que el neoliberalismo dejara opciones). Si bien parece preferible la seguridad de la amistad ante la inseguridad del amor, es que necesitamos un mínimo de mundo frente a la destrucción de la vida. Un mínimo de mundo: no hogares (con paredes de 
cemento y chimeneas prendidas todo el invierno), sino cabañas ${ }^{6}$.

Es paradójico y hermoso a la vez que a veces se es feminista sin quererlo. O se aporta al feminismo de refilón, para no tomarnos tantas atribuciones sobre este pasaje. Pero me pareció que esta "cabaña”, más que muchas otras reflexiones sobre el "amor romántico" que también se han popularizado en los feminismos, aportarían bastante a una manera mucho menos culpabilizante e individualista para la salida al mandato afectivo heteronormativo, o la eterna camisa de fuerza para las mujeres entre cupiditas y caritas.

Constanza Michelson es psicoanalista y columnista habitual en varios medios de comunicación. Hasta que valga la pena vivir es una colección de ensayos que tienen por característica una de las principales habilidades de la autora: el talento para la divulgación y para poner a dialogar sobre todo al psicoanálisis, pero también lecturas filosóficas o literarias con temas de la "vida diaria", con la coyuntura o con acontecimientos políticos de actualidad. Nuevamente la redacción del libro se encuentra con la revuelta de octubre y esta se cuela, naturalmente, en la afectividad de su redacción y en las hipótesis y preguntas que ya venía trazando sobre "el deseo perdido y el capitalismo del yo" que es el subtítulo de este volumen. "Hasta que valga la pena vivir" es una de las consignas más potentes y conmovedoras de la revuelta de octubre: de todo el universo de micro y macro demandas que se organizaron en vistosos carteles, disfraces y grafitis, esta frase es particularmente precisa sobre lo que se juega o parece haber hecho estallar esta revuelta: la precariedad de la vida, la vida endeudada en cuotas y la deuda de una vida plena o, al menos, de algo a lo que le podamos llamar vida.

Como he mencionado, el libro de Michelson se reconoce como una reflexión sobre el deseo, y la revuelta de octubre ayuda a nutrir sus tesis y preguntas en torno a un régimen de vida en que el deseo está atravesado por un yo confiado de su existencia que se reduce a un consumidor, que ha sido modelado por el capitalismo financiero. Para la autora, el deseo siempre el lugar de inscripción para decir "deseo" es el psicoanálisis, aunque estos ensayos no pretenden ser un documento académico en torno a los conceptos que se movilizan- no puede llevar una buena relación con el neoliberalismo, pues este último inevitablemente confunde deseo con compulsión o fragmentación con autodeterminación. Eso es lo que ha estallado en octubre, afirma Michelson.

${ }^{6}$ Ibid., 100. 
Este libro, como el de Messina, está cruzado por otras revueltas. La revuelta del Mayo Feminista de 2018, por lo pronto. Aunque no sea el tema que recorre todos los ensayos, sí hay una voluntad por leer una suerte de "clima de época" que permite comprender por qué la revuelta feminista o la de octubre de 2019 han tomado las direcciones, consignas y banderas que han tomado. Hay también una atención puesta en la deriva moral y punitiva, una preocupación por comprender qué puede significar en estos tiempos "del yo" el desmontar el amor romántico, criticar el mandato heterosexual, o resistirse ante viejos adagios como aquel que dice que "el amor duele" -adagios que ya sea desde la mayor popularidad de los feminismos o el trabajo importantísimo de las redes feministas contra la violencia, ha intentado revertirse en consignas como "si duele no es amor", "quien ama no mata, no humilla, ni maltrata"; fórmulas todas que en determinados contextos, y que con extensas campañas han aportado a tensionar y visibilizar la violencia de género-. Hago esta salvedad porque me parece que es cierto que hay algo de recuperación en clave individualista de estas consignas, que no es posible pensar que su circulación será leída solo como el panfleto contra la violencia que muchas veces les dio lugar y aparición. En esto, el texto de Constanza Michelson nos ayuda a reflexionar.

Dado que la autora afirma que vivimos en una ficción del yo sin límites, en donde la voluntad puede deconstruirse y reconstruirse para asemejarse al ideal, la ansiedad termina siendo uno de los afectos que definen estos tiempos. Son tiempos de cuerpos que no pueden esperar, que no resisten no saber porque no pueden controlar todo a través del "yo quiero", tiempos de la "exacerbación del narcisismo y cuerpos apanicados y deprimidos"7. Este énfasis en el "yoísmo" de la época, y una suerte de "descorporalización" de la política que niega el deseo (o no lo permite), que despersonaliza los conflictos, niega la alteridad y atraviesa la vida sexual y sentimental, genera una suerte de confusión en el que los asuntos personales se visten de ropajes políticos, esencializando la demanda de reconocimiento sin dar lugar a la posibilidad de lo incierto, de lo trágico o de que esa alteridad se despliegue en su dimensión más radical: como aquello que no es posible de ser asido.

El discurso de la mujer empoderada, la literatura de autoayuda y la superación personal, la liberación sexual, serían todos relatos que conspiran, o mejor dicho, serían parte

\footnotetext{
${ }^{7}$ Constanza Michelson, Hasta que valga la pena vivir. Ensayos sobre el deseo perdido y el capitalismo del yo (Santiago: Editorial Planeta), 24.
} 
de arengas individualistas y funcionales a la subjetividad neoliberal. Con esto, Michelson ofrece una hipótesis que es necesaria de observar:

No es casual que esta ola feminista reviente por el lado más íntimo, el de la vinculación sexual. No se trata esta vez de algunas demandas puntuales, ni siquiera de la búsqueda de igualdad, sino de interrogar el deseo sexual mismo. Por eso la insistencia en la deconstrucción del amor romántico, de las lógicas de la seducción, la resignificación del abuso sexual ${ }^{8}$.

Me parece interesante poner atención en esta cita porque hay, de hecho, un lado de esta "ola" (prefiero la palabra marea por sus flujos y reflujos) feminista que revienta por el lado íntimo, por el lado del amor y la vinculación sexual. Pero también lo hace por el lado del aborto, de la lucha contra el extractivismo, de darle continuidad a las demandas estudiantiles que se fueron azumagando desde su explosión el 2011, de la exigencia por una educación no sexista en un país repleto de candados conservadores, y de un contexto - nuevamente lo repito- en que los "buses de odio" vuelven recargados y con cancha abierta desde gobiernos conservadores y grupos religiosos con poder político y económico. No es la primera vez que los feminismos interrogan la moral sexual, ni tampoco que esencializan posiciones en la figura de "la mujer", la madre o la diferencia sexual. No es tampoco la primera vez en que el feminismo es abolicionista, separatista o grita consignas como "Muerte al Macho" (pensemos en el manifiesto SCUM, por lo bajo $^{9}$ ). Pero es cierto, es necesario hacerse la pregunta de por qué así y por qué ahora fue así. Porque es cierto que en tiempos de fragmentación la desvinculación sexual, la respuesta "poliamorosa", las críticas a la familia o los lesbianismos militantes pueden ser sospechosos, pero también impugnan a la heterosexualidad obligatoria y su régimen de organización social y cultural. Insisto que me parece importante no perder de vista la crítica y mostrar los peligros del punitivismo. ¿Cómo podríamos hacer política con las mismas "herramientas" que nos dañan? La "funa", la exposición, el señalamiento, la falta de pruebas para juzgar a otros, son evidentemente peligrosas, y urge pensar otros imaginarios posibles, otros guiones. Sin justificar, me parece, la autora propone una reflexión que es, sin duda, pertinente:

\footnotetext{
${ }^{8}$ Ibid., 37.

${ }^{9}$ Valerie Solanas, Manifiesto SCUM (Barcelona: Editorial Herstory, 2008).
} 
En todo caso, quizás sea justo y necesario que el feminismo deba levantar estas nuevas prescripciones durante la revuelta, porque, a fin de cuentas, al menos en la heterosexualidad, son las mujeres quienes han padecido el mal de la seducción, pero bajo otro nombre: el enamoramiento o los apegos feroces. Han sido principalmente ellas quienes se han desviado en lo amoroso, no porque amen más, sino porque en general los cuerpos femeninos (de la anatomía que sea) son los que están seducidas con el amor, se enamoran del amor, a veces no del otro, aunque eso confunda ${ }^{10}$.

Es como una suerte de momento jacobino, pienso, pero es por cierto necesario imaginar más allá de los límites que impone la negación del otro, y también sobre la posición ética de vivir entre matices. De decidir qué se hará con el abusador que no tiene sanción legal porque el crimen está prescrito, o porque aquello que cometió no es judicializable. Parte de esa discusión es la que nos tensiona en los feminismos, porque hay cuestiones que no tienen resolución legal, simplemente. Michelson pone énfasis en la forma en que las mujeres se han podido encontrar en solidaridades de género, en códigos de lo deseable. Y aunque quedan cosas por hacer, emergen también formas que dan cuenta no solo de otros imaginarios para la política, sino que de cierta astucia para moverse entre las clásicas definiciones de la mujervíctima o la mujer-amante. Pensemos, por ejemplo (y esto lo introduzco yo), en el efecto dinamizador de la performance de Las Tesis, que en conmemoración del 25 de noviembre de 2019 se convierte en un acontecimiento político a escala global que tiene efecto por su capacidad paródica (contra el "cuidado" de la policía a las mujeres), pero también porque al introducir el problema de la violencia sobre el cuerpo de las mujeres genera un efecto identificatorio. El asunto es, entonces, moverse entre afirmación y negación, entre crítica y demanda de justicia o inclusión. Otros viejos temas del feminismo.

Asamblea de los cuerpos, de la filósofa Alejandra Castillo, se publica con el interés expreso de analizar y proponer ideas sobre el momento destituyente-instituyenteconstituyente que abrió la revuelta de octubre. Ensayos breves, en su mayoría publicados en

${ }^{10}$ Ibid., 45. 
el blog "Antígona feminista" ", desde donde Castillo reflexiona e invita a otras y otros a publicar en torno a temas de coyuntura y reflexión política. Textos urgentes también; respuestas que aparecieron muchas veces después de asonadas represivas, del "Acuerdo por la paz" de noviembre de 2019, o también análisis que siguieron el curso de investigaciones que la autora lleva elaborando durante años, como la cuestión del cuerpo de la política y la necesidad de pensarlo descentrado del mandato heteronormado que establece un orden androcéntrico fijado en la diferencia sexual. Fue la revuelta de octubre, claro, la que marcó el tempo de estos escritos, pero el Mayo Feminista aparece como un momento que inauguró un "no más" a los mandatos del cuerpo de la élite y los abusos del Estado autoritario y patriarcal. Este "no más" se agrupó además en un conjunto de frases que, para el neoliberalismo, según Castillo, son imposibles de procesar. Frases que abrieron sentidos para la revuelta, que marcaron otro tiempo: detenciones de tráfico, suspensiones de actividades, la puesta en suspenso del orden dominante como una expresión de querer cambiarlo todo. La consigna "evadir, no pagar, otra forma de luchar" se despliega allí, para la autora, como un significante vacío que encadena las luchas y protestas de los últimos años, que desafía la apatía y el consenso neoliberal y las moderadas políticas liberales (feministas y no feministas) de la postdictadura. La revuelta abrió un tiempo de incertezas, porque de eso se trata ese tiempo otro. Demandó todo: la muerte del neoliberalismo, el encuentro de los cuerpos en la calle, en la asamblea, en la solidaridad: "La protesta no para y se vuelve asamblea, deliberación, conversación y solidaridad. Un cuerpo multitudinario, una asamblea de cuerpos que se autoconvoca en plazas, escuelas, universidades, oficinas, centros de vecinas y vecinos, y decide que ya no va más el modelo político económico: así no"12.

La Asamblea Constituyente se vuelve un nudo clave en la reflexión de Alejandra Castillo. Es ésta y no otra, la expresión que podría poner en entredicho los intereses de la élite y multiplicar los cuerpos que puedan colapsar y suspender el orden androcéntrico de la política tradicional, de la "gran política", aquella que se ha basado en los consensos racionales. Una asamblea es una puesta "en relación de vidas, experiencias y cuerpos que en principio no tienen nada en común más que el deseo de reunirse. La asamblea es una salida

\footnotetext{
${ }^{11}$ Ver el blog en https://antigonafeminista.wordpress.com/.

${ }^{12}$ Castillo, Asamblea de los cuerpos, 44.
} 
del individualismo posesivo para entregarse a la conversación sin cálculo, tal vez porque una asamblea se reúne en torno a palabras sin guiones predefinidos" ${ }^{\prime 13}$.

Aquí no se gana ni se pierde, se busca la mirada del otro, se establece un "en común". Para la autora el tiempo de la revuelta, además de estar descrito por el signo de la suspensión, ha sido un tiempo acelerado. Todo ocurre rápido y se puede conocer solo de manera parcial, nos habita la sensación de no saber qué pasa, al mismo tiempo que necesitamos enterarnos de todo lo que pasa y eso, por cierto, conspira contra la productividad y nuestra producción de certezas. A este tiempo acelerado, propone Castillo, lo define la parcialidad, es opaco, vertiginoso y encuentra algo de tranquilidad en la reunión, el encuentro, el canto, el baile.

\section{Del encuentro de estos textos}

Decía en un comienzo, que me parece que a estos textos los podría agrupar un deseo de preguntas y también unos “téngase presente” feministas. Son libros disímiles, afectivamente, teóricamente, y asumen posiciones radicalmente distintas en su manera de encarnar el feminismo. Esto, por supuesto, no es un problema en sí mismo. Se puede hablar de feminismos sin ser feminista, aunque hay acaloradas y extensas reflexiones en torno a aquello. Sobre todo, en lo que significa "ser" feminista. El feminismo ha suscitado interés los últimos años, de eso no hay duda: los movimientos feministas han interpelado, permeado y tomado voz en el espacio público a través de reivindicaciones muy sentidas, como por ejemplo el problema de la violencia contra las mujeres y las disidencias. La capacidad de interpelación que estos movimientos tienen no guarda relación únicamente con un vaciamiento de la política tradicional, sino con el sostenido trabajo de visibilización y denuncia de muchos colectivos en torno al gravísimo problema que representan los feminicidios; pero no solo la violencia corporal, también la reproducción social del capital, la distribución generizada de los cuidados, y claro, la dimensión de violencia que estos problemas también comportan.

Lo vertiginoso de estos tiempos de revuelta, de este tiempo acelerado, no solo apuntan a la parcialidad de la información que procesamos o alcanzamos a mirar, sino que también al

\footnotetext{
${ }^{13}$ Ibid., 79.
} 
marco que nos permite ver o no ver lo que se está gestando a nivel político. Es cierto, durante años no notamos que la posdictadura permitiera "correr cercos" institucionales, pero la verdad es que es posible atisbar procesos, mini revueltas, articulaciones y modificaciones en el campo de la política tradicional, pero por sobre todo, en la organización de la asamblea de los cuerpos, como diría Castillo. Hago referencia al marco porque me parece pertinente dada la lectura de estos libros en conjunto, diálogo y tal vez, también, perspectiva: dar cuenta de cómo las lecturas en torno a la revuelta feminista y la revuelta de octubre pueden suscitar énfasis diversos, preocupaciones de variadas índoles, y puntos políticos sustantivamente heterogéneos.

Creo que los tres libros acuerdan en la potencia imaginativa del feminismo y su capacidad de "revolucionar la revolución", pero no sé si la consigna "la revolución será feminista o no será" apunta a recuperar ese horizonte o, más bien, a distorsionar el imaginario revolucionario patriarcal. Hay mucho de paródico en las consignas feministas, y las redes sociales y los movimientos más conservadores saben entrampar bastante bien la discusión en la literalidad de las frases: encajonarnos en si acaso de verdad las feministas quieren matar machos, destruir a los hombres o abortar por deporte. Creo que estos libros aportan a elaborar preguntas profundas -por ejemplo, aquella de Messina sobre el Mal radical-, pero no deben descuidar el marco desde donde se inscriben ciertas críticas. Los feminismos no han pasado por alto la pregunta por el punitivismo, al mismo tiempo que se enfrentan a la acción concreta y a las fallas de sus políticas, a las equivocaciones y opacidades de las decisiones. Tal vez el tiempo de la revuelta ha dado posibilidad de lidiar de mejor manera con lo incierto, con la angustia. Lo mismo vale para el escenario Covid-19 y esta situación de distanciamiento y espera de una vacuna que nos devuelve a la indefensión, pero también a encontrarnos de frente con los problemas estructurales del patriarcado: las mujeres cuidamos más, y pasar más tiempo en casa puede traernos peligro de muerte.

Una perspectiva de análisis situado de los feminismos -cuerpos que no solo reflexionan desde la mirada teórica, sino que también desde lo que les toca encarnar como cuerpos generizados, racializados, sexualizados- permite ver cuestiones que de otro modo no se ven, y lamentablemente muchos aparatajes teóricos (como la filosofía o el psicoanálisis) han contrabandeado en neutralidad el orden androcéntrico. Alejandra Castillo se afirma en el "no más" de la revuelta feminista para dar cuenta de una negación corpo- 
política al patriarcado, pero en otras oportunidades ha dedicado extensos pasajes en dar cuenta sobre el género de la filosofía, sobre el orden masculino que ha cruzado el pensamiento. Por cierto, no reviste obligación pensar en aquella clave, pero una reflexión sobre el feminismo debiera al menos desmontar sus propios supuestos.

Si el tiempo de la revuelta es un "no más", una apertura hacia otros imaginarios y hacia lo incierto, quisiera pensar que estos textos permitirán no solo seguir exigiendo el encuentro, la asamblea, las cabañas; también nos harán pensar en torno a lo que no podemos repetir, a la opacidad del deseo que es también una política antineoliberal, a la posibilidad de equivocarnos y también de enlazarnos, encontrarnos, acuerparnos. Hay muchos feminismos, "hay movimiento y campo feminista", como le escuché en una conferencia a la filósofa Luciana Cadahia hace unos meses. Salir del "yoísmo" es también pensar más allá de la política del sujeto (feminista), para incluir el campo de las correlaciones de fuerza: las asambleas.

\section{Libros reseñados}

Castillo, Alejandra. Asamblea de los cuerpos. Santiago: Sangría Editora, 2019. 83 pp. ISBN 978-9568691562.

Messina, Aïcha Liviana. Feminismo y revolución. Crónica de una inquietud. Santiago 2019. Fragmentos de una paz insólita. Santiago: Ediciones Metales Pesados, 2020. 120 pp. ISBN 9789566048176.

Michelson, Constanza. Hasta que valga la pena vivir. Ensayos sobre el deseo perdido y el capitalismo del yo. Santiago: Editorial Planeta, 2020. 198 pp. ISBN 9789569987243. Ebooks Patagonia. 


\section{Referencias bibliográficas}

Cuello, Nicolás y Lucas Morgan compiladores. Críticas sexuales a la razón punitiva. Insumos para seguir imaginando una vida junt*s. Neuquén: Ediciones Precarias, 2018.

Mackinnon, Catherine. "Crímenes de guerra, crímenes de paz". En Los derechos humanos, las conferencias Oxford Amnesty de 1993, S. Shure y S. Hurley editores. Madrid: Editorial Trotta, 1998.

Solanas, Valerie. Manifiesto SCUM. Barcelona: Editorial Herstory, 2008.

\section{Sobre la autora}

Karen Glavic. Doctoranda en Filosofía con mención en Estética y Teoría del Arte en la Universidad de Chile (Santiago, Chile). Ha publicado recientemente Aborto libre. Materiales para la lucha y la discusión en Chile (Santiago: Pólvora Editorial, 2019) e "Insistencias feministas en la filosofía chilena de la postdictadura", Cuyo - Anuario de Filosofía Argentina y Americana 36 (2019): 55-72. Es editora de la colección Feminismos en Pólvora Editorial. Correo electrónico: karenglavic@gmail.com. 